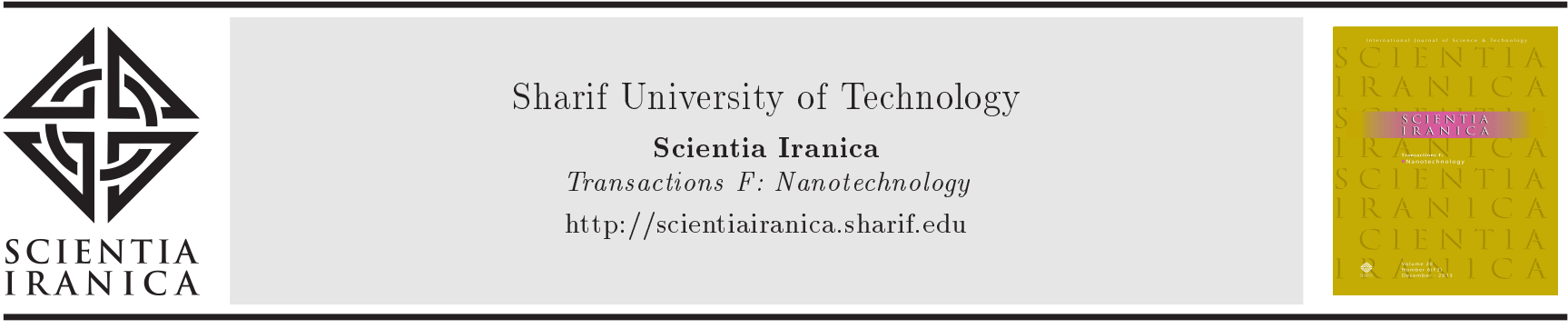

\title{
Effect of $\mathrm{HCl}$ on the structure and catalytic activity of $\mathrm{Pt} / \mathrm{Al}_{2} \mathrm{O}_{3}$ nanocatalyst prepared in microemulsion system
}

\author{
A. Keshavarz ${ }^{a}$ and A. Salabat ${ }^{a, b, *}$ \\ a. Department of Chemistry, Faculty of Science, Arak University, Arak, 38156-8-8349, Iran. \\ b. Institute of Nanosciences \& Nanotechnolgy, Arak University, Arak, 38156-8-8349, Iran. \\ Received 29 September 2017; received in revised form 15 January 2018; accepted 14 May 2018
}
KEYWORDS
Nanocatalyst;
Pt nanoparticles;
Microemulsion;
Shape-controlled
catalyst;
Catalyst activity.

\begin{abstract}
Nowadays, preparation of special and effective nanocatalysts is a hot research topic. Obviously, the size and structure of the active site of a catalyst plays a key role in catalytic activity. In this novel research, the $\mathrm{Pt}$ nanocatalyst supported on $\gamma-\mathrm{Al}_{2} \mathrm{O}_{3}$ was prepared in two different microemulsion systems to clarify the effect of microemulsion essence on catalyst character and activity. Two types of microemulsion systems were constructed from Triton X-100/2-butanol as surfactant and co-surfactant, i.e., n-heptane as organic phase and $\mathrm{H}_{2} \mathrm{O}+\mathrm{H}_{2} \mathrm{PtCl}_{6}$ (or $\mathrm{HCl}(\mathrm{aq})+\mathrm{H}_{2} \mathrm{PtCl}_{6}$ ) as aqueous phase, to investigate the effect of $\mathrm{HCl}$ on the shape and structure of the prepared nanocatalysts. Shape, size, and size distribution of the Pt nanoparticles on the alumina were monitored by cyclic voltammetry and SEM analysis. Activity of the nanocatalysts was determined by reduction of $p$-nitrophenol as a reaction model.

(C) 2019 Sharif University of Technology. All rights reserved.
\end{abstract}

\section{Introduction}

In recent years, the number of research studies in the field of catalysis has grown remarkably because of environmental and industrial needs, such as the need to remove air pollutants or the proposition of alternative energy sources. These studies aimed to investigate the influence of shape, size, size distribution, and composition of surface sites of the catalysts on their activity [1$3]$. With the advent of nanotechnology and its application in catalytic reaction, the major step has been taken to design novel nanocatalysts [4-6]. The fabrication of metal nanoparticles with shape control and sizes

\footnotetext{
*. Corresponding author. Tel.: +98 86 32627530; Fax: +988634173406

E-mail addresses: a-salabat@araku.ac.ir (A. Salabat); a-keshavarz@phd.araku.ac.ir (A. Keshavarz).
}

is critical for catalytic applications. This subject has been confirmed by investigating platinum nanoparticle morphology, prepared in the presence of different capping polymers on their catalytic properties [7].

Long et al. prepared polyhedral and nonpolyhedral Pt nanoparticles by a modified polyol method using $\mathrm{AgNO}_{3}$ as a structure-modifying agent [8]. In addition, they reported on a polyol method used for fabricating stabilized Pt nanoparticles (Pt NPs) as cubic and octahedral shapes [9]. In another research work, published recently by Arán-Ais et al.[10], preferentially oriented (100) Pt NPs were synthesized by different methodologies and studied electrochemically.

Cuenya et al. published a review on the role of nanoparticle size and shape in chemisorption and catalytic performance [11]. They discussed the effect of the nanoparticles' shape and atomic structures on catalytic performance. Martinez-Rodriguez et al. synthesized Pt NPs by microemulsion method at different 
$\mathrm{HCl}$ or $\mathrm{H}_{2} \mathrm{SO}_{4}$ concentrations $[12,13]$. They confirmed that cubic $\mathrm{Pt}$ nanoparticles could be obtained in the presence of $\mathrm{HCl}$ or $\mathrm{H}_{2} \mathrm{SO}_{4}$. In addition, they reported that the optimal $\mathrm{HCl}$ percentage in the water phase should be about $25 \%$ to obtain the highest amount of cubic nanostructures [14].

Further to our research works [15-17] and other literature results, we are encouraged to fabricate, for the first time, $\mathrm{Pt} / \gamma-\mathrm{Al}_{2} \mathrm{O}_{3}$ nanocatalyst with controlling shape of $\mathrm{Pt} \mathrm{NPs}_{\mathrm{s}}$ dispersed on alumina using microemulsion systems. For this purpose, two different w/o microemulsion systems containing $\left(\mathrm{H}_{2} \mathrm{O}+\mathrm{H}_{2} \mathrm{PtCl}_{6}\right) / n$-heptane/Triton $\mathrm{X}-100 / 2$ butanol and $\left(\mathrm{HCl}(\mathrm{aq})+\mathrm{H}_{2} \mathrm{PtCl}_{6}\right) / n$-heptane/Triton $\mathrm{X}-100 / 2$-butanol were used to prepare $\mathrm{Pt} / \gamma-\mathrm{Al}_{2} \mathrm{O}_{3}$ nanocatalysts. The shape of the prepared Pt NPs in these two types of microemulsion systems was monitored electrochemically. Characterization of the synthesized nanocatalysts was also performed by XRD and SEM analysis. To determine catalytic activity of the nanocatalysts with different structures, reduction of $p$ NP over the prepared nanocatalysts was investigated.

\section{Experimental procedures}

\subsection{Materials}

Hexachloroplatinic acid $\left(\mathrm{H}_{2} \mathrm{PtCl}_{6}\right)(99 \%), n$-heptane, 2-butanol, and $p$-nitrophenol $(p$-NP) were obtained from Merck Company and used as received. The nonionic surfactant poly(ethylene glycol) $p$-(1,1,3,3tetramethylbutyl)-phenyl ether (TX-100) with purity of $98 \%$ was purchased from Acros Company and used without further purification. Alumina $\left(\gamma-\mathrm{Al}_{2} \mathrm{O}_{3}\right)$ was obtained from Japan Aerosil with the surface area of $110 \mathrm{~m}^{2} / \mathrm{g}$. All of the solutions were prepared by deionized water.

\subsection{Preparation of Pt colloidal system}

A colloidal system of platinum nanoparticles was prepared using a w/o microemulsion composed of $n$ heptane as oil phase, nonionic surfactant of TX-100, and co-surfactant of 2-butanol. Then, a suitable amount of $0.1 \mathrm{M}$ aqueous solutions of $\mathrm{H}_{2} \mathrm{PtCl}_{6}$, prepared in pure water or aqueous $25 \% \mathrm{HCl}$, was added to a solution of $n$-heptane, TX-100, and 2-butanol to obtain microemulsion systems. Typical volume percentage of the microemulsion system includes $3 \%$ $\mathrm{H}_{2} \mathrm{PtCl}_{6}$ solution, $40.5 \% n$-heptane, $16.5 \%$ TX-100, and $40 \%$ 2-butanol. The prepared microemulsion systems were stirred and settled down for 3 hours to equilibrate. Afterwards, the platinum precursor was reduced to the metallic $\mathrm{Pt}$ nanoparticles with the addition of NaBH4 to the microemulsion systems. In all experiments, the reducing agent $\left(\mathrm{NaBH}_{4}\right)$ to $\mathrm{Pt}$ molar ratio was kept at 10 . The two different types of $\mathrm{Pt}$ colloidal systems (synthesized without and with $\mathrm{HCl}$ ) are now ready for characterization or precipitation on the support and for producing nanocatalyst samples.

\subsection{Fabrication of $\mathrm{Pt} / \gamma-\mathrm{Al}_{2} \mathrm{O}_{3}$ nanocatalysts}

In order to prepare the nanocatalysts' samples, the support of catalyst $\left(\gamma-\mathrm{Al}_{2} \mathrm{O}_{3}\right)$ was added to the platinum colloidal systems. Then, Pt nanoparticles were harvested from colloidal suspensions with the dropwise addition of THF to precipitate platinum particles on the alumina support. Subsequently, the produced nanocatalysts of $\mathrm{Pt} / \gamma-\mathrm{Al}_{2} \mathrm{O}_{3}$ were dried at room temperature for two days and, then, calcined at $600^{\circ} \mathrm{C}$ for 2 hours.

\subsection{Characterization of nanocatalysts}

A Philips diffractometer with $\mathrm{Cu} \mathrm{K} \alpha$ radiation $(\mathrm{Cu}$ $\mathrm{K} \alpha_{1}: 1.54056 \AA, \mathrm{Cu} \mathrm{K} \alpha_{2}: 1.54439 \AA$ ) was used to carry out X-ray diffraction (XRD) experiment on the produced nanocatalysts at room temperature. The $2 \theta$ angular region, with the step time of $0.02 \mathrm{~s}$, between $20^{\circ}$ and $80^{\circ}$, was considered.

To determine the size and size distribution of $\mathrm{Pt}$ NPs precipitated on alumina, the Scanning Electron Microscope (SEM) was applied using a MIRA3 TESCAN instrument.

The electrochemical characterization, as Cyclic Voltammetry (CV), of the platinum nanoparticles was carried out in an electrochemical cell with three electrodes. An AUTOLAB system of 101 (Eco Chemie $\mathrm{Bv}$, the Netherlands) was used to control the electrode potential. A platinum wire was used as a counter electrode. To run the electrochemical experiments, the potentials were measured against a Reversible Hydrogen Electrode (RHE). A gold collector electrode was used to deposit the platinum nanoparticles over it and, finally, polished with alumina powder before each experiment. The electrolyte used for electrochemical characterization of the prepared electrode was $0.5 \mathrm{M}$ of $\mathrm{H}_{2} \mathrm{SO}_{4}$ solution. The method for cleaning the $\mathrm{Pt}$ nanoparticles and $\mathrm{CV}$ condition was adjusted, as can be found in [13].

\subsection{Catalytic activity test}

In order to determine catalytic activity of the synthesized nanocatalysts with different structures, reduction of $p$-NP over the prepared nanocatalysts was investigated as a reaction model. The catalytic reduction of $p$-NP was performed in a stainless steel autoclave. The amount of $0.1 \mathrm{~g}$ catalyst and $10 \mathrm{ml}$ aqueous solution of $p$-NP (with the initial concentration of $20 \mathrm{ppm}$ ) were added to the autoclave and sealed. In order to remove air, the autoclave was purged with hydrogen gas. Then, hydrogen gas was introduced into the reactor to a desired pressure. Finally, the hydrogenation reaction was performed at $303 \mathrm{~K}$ and 1 atm. The hydrogenation reaction progress was monitored by the intensity of the characteristic peak of 
$p$-NP at $400 \mathrm{~nm}$ using the UV-vis spectrophotometer [18]. Catalytic conversion of $p$-NP reduction was calculated through the following equation:

$$
\text { Conversion } \%=\frac{C_{0}-C_{t}}{C_{0}} \times 100,
$$

where $C_{0}$ is the initial concentration of $p$ - NP, and $C_{t}$ is the concentration at various times of $t$.

\section{Results and discussion}

\subsection{SEM analysis of the prepared nanocatalysts}

The obtained SEM images of pristine $\gamma-\mathrm{Al}_{2} \mathrm{O}_{3}$ and $\mathrm{Pt} / \gamma-\mathrm{Al}_{2} \mathrm{O}_{3}$ nanocatalysts, prepared in $\mathrm{H}_{2} \mathrm{O}-$ microemulsion and $\mathrm{HCl}(\mathrm{aq})$-microemulsion, are shown in Figure 1. It was found that the catalyst kept the layer structure of the $\gamma-\mathrm{Al}_{2} \mathrm{O}_{3}$ support and $\mathrm{Pt}$ nanoparticles well dispersed on the support. As can be seen from the size distribution histogram of Figure 1, the size of $\mathrm{Pt}$ nanoparticles is populated in the range of 2-10 nm for $\mathrm{H}_{2}$ O-microemulsion and 10-20 nm for $\mathrm{HCl}(\mathrm{aq})$-microemulsion. Martínez-Rodríguez et al. observed the growth of the Pt particle size by increasing $\mathrm{HCl}$ concentration [13]. These results confirm that the growth step of the nanoparticles' synthesis in microemulsion systems depends considerably on the environmental conditions of the reaction.

\subsection{X-ray diffraction spectroscopy of the prepared nanocatalyst}

XRD patterns of the $\mathrm{Pt} / \gamma-\mathrm{Al}_{2} \mathrm{O}_{3}$ nanocatalyst samples, prepared in $\mathrm{H}_{2} \mathrm{O}$-microemulsion and $\mathrm{HCl}(\mathrm{aq})$ microemulsion, are shown in Figure 2. The main reflection angles shown in Figure 2, related to $\gamma-\mathrm{Al}_{2} \mathrm{O}_{3}$ or $\mathrm{Pt}$,

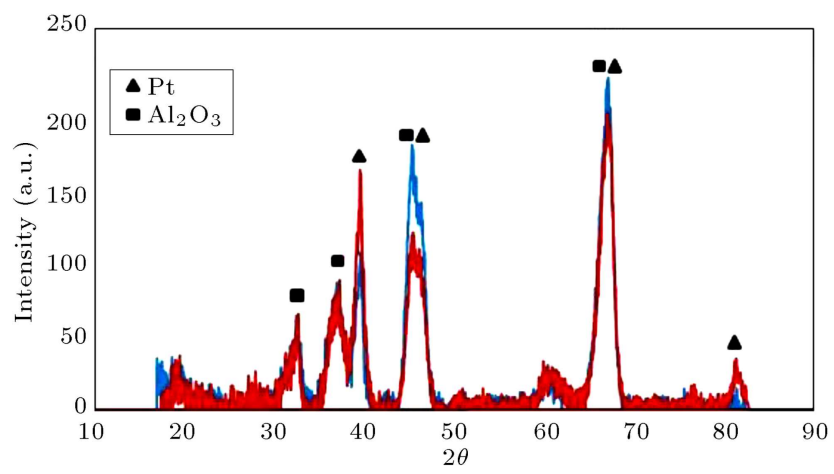

Figure 2. XRD patterns for $\mathrm{Pt} / \gamma-\mathrm{Al}_{2} \mathrm{O}_{3}$ nanocatalysts (blue line) prepared in $\mathrm{HCl}-$ microemulsion and (red line) in $\mathrm{H}_{2} \mathrm{O}$-microemulsion systems.

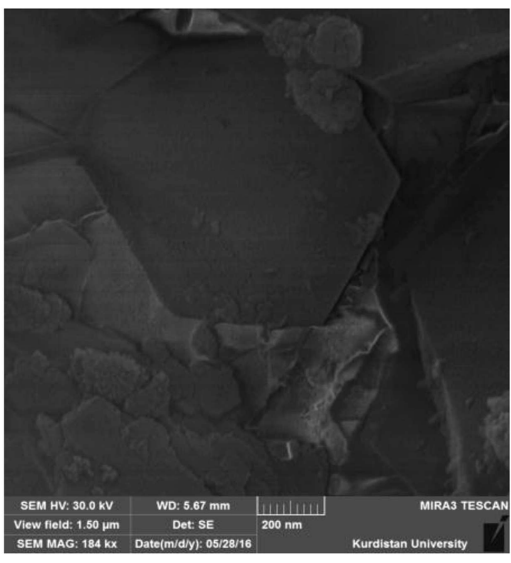

(a)

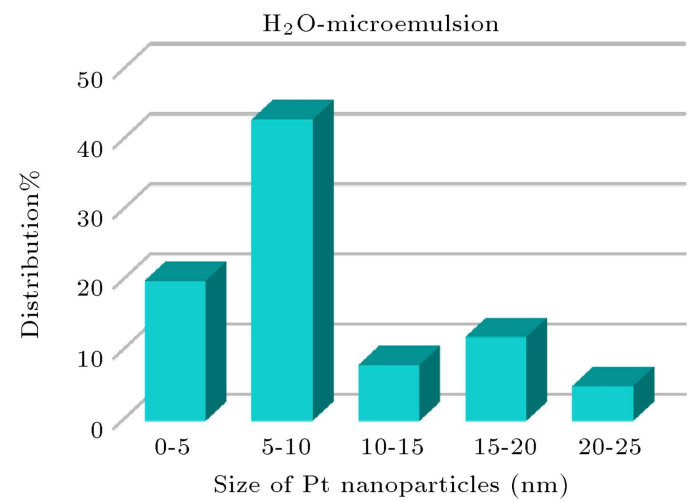

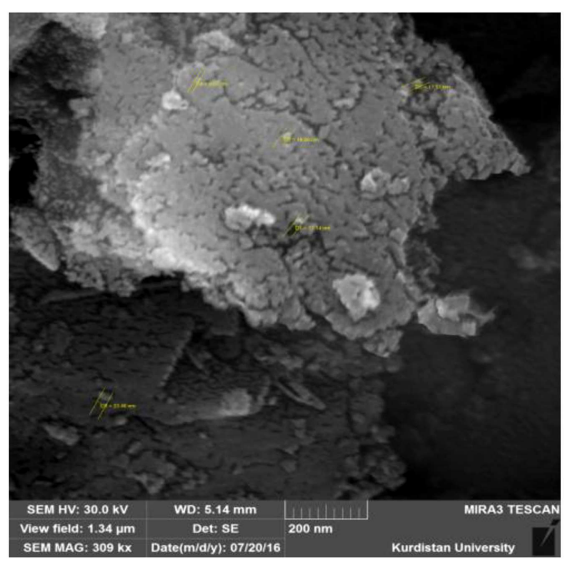

(b)

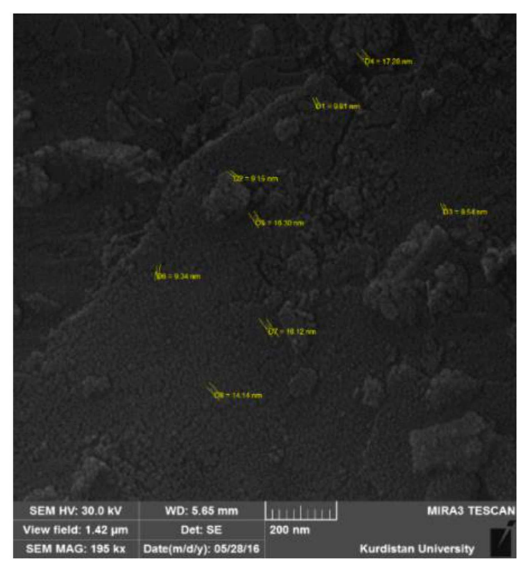

(c)

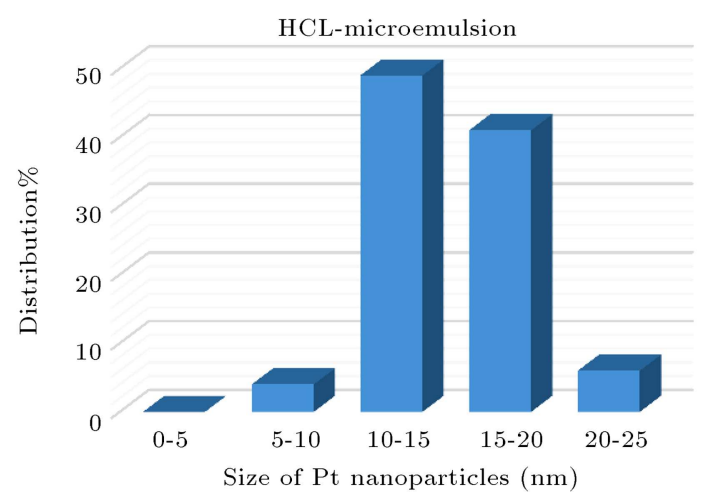

Figure 1. SEM images of (a) $\gamma-\mathrm{Al}_{2} \mathrm{O}_{3}$, (b) $\mathrm{Pt} / \gamma-\mathrm{Al}_{2} \mathrm{O}_{3}$ prepared in $\mathrm{H}_{2} \mathrm{O}-$ microemulsion, and (c) $\mathrm{Pt} / \gamma-\mathrm{Al}{ }_{2} \mathrm{O} 3 \mathrm{prepared}$ in HCl-microemulsion and particle size distribution histogram of fabricated nanocatalysts. 
have been approved by literature data. The reflection angles of $2 \theta=39.8^{\circ}, 46.4^{\circ}$, and $66.8^{\circ}$ correspond to $\operatorname{Pt}(111), \operatorname{Pt}(200)$, and $\operatorname{Pt}(220)$, respectively. As can be seen from XRD patterns, the two last peaks are overlapped at the same angles with alumina reflection data. As an interesting result, the intensity of surface (111) has been reduced and surface (200) increased for $\mathrm{Pt}$ nanoparticles synthesized in $\mathrm{HCl}(\mathrm{aq})$-microemulsion system.

\subsection{Electrochemical results}

Cyclic voltammetry experiment on platinum nanoparticles, prepared in $\mathrm{H}_{2} \mathrm{O}$-microemulsion and $\mathrm{HCl}(\mathrm{aq})$ microemulsion systems, was used to distinguish the effect of $\mathrm{HCl}$ on the shape of $\mathrm{Pt}$ particles. As reported by several investigations of $\mathrm{CV}$ for $\mathrm{Pt} \mathrm{NPs}$ $[13,14,19]$, four characteristic peaks of $0.12,0.27,0.37$, and $0.53 \mathrm{~V}$ versus RHE should be observed. These peaks correspond to (110) sites, (100) steps and terrace borders, (100) terraces or wide domains, and (111) sites, respectively. Figure 3 shows $\mathrm{CV}$ for two types of nanoparticles, prepared in $\mathrm{H}_{2} \mathrm{O}$-microemulsion and $\mathrm{HCl}(\mathrm{aq})$-microemulsion systems. As observed from $\mathrm{CV}$ results, the peak areas at 0.27 and $0.37 \mathrm{~V}$ considerably increased when $\mathrm{Pt}$ NPs were synthesized in $\mathrm{HCl}(\mathrm{aq})$ microemulsion system, whereas the peak areas at 0.12 and $0.53 \mathrm{~V}$ decreased. The quantity of (111) sites is nearly negligible for the nanoparticles prepared in $\mathrm{HCl}$ (aq)-microemulsion system, which coincides with other observations $[13,19]$.

\subsection{Catalytic activity results}

The hydrogenation reaction of $p$-NP, as a reaction model, over the $\mathrm{Pt} / \gamma-\mathrm{Al}_{2} \mathrm{O}_{3}$ nanocatalysts was investigated to determine the effect of $\mathrm{HCl}$ in the fabrication process of catalyst on the catalyst activity. It is well known that Pt nanoparticles facilitate electron transfer from $\mathrm{H}_{2}$ molecule, as a donor, to $p$-NP molecule as an

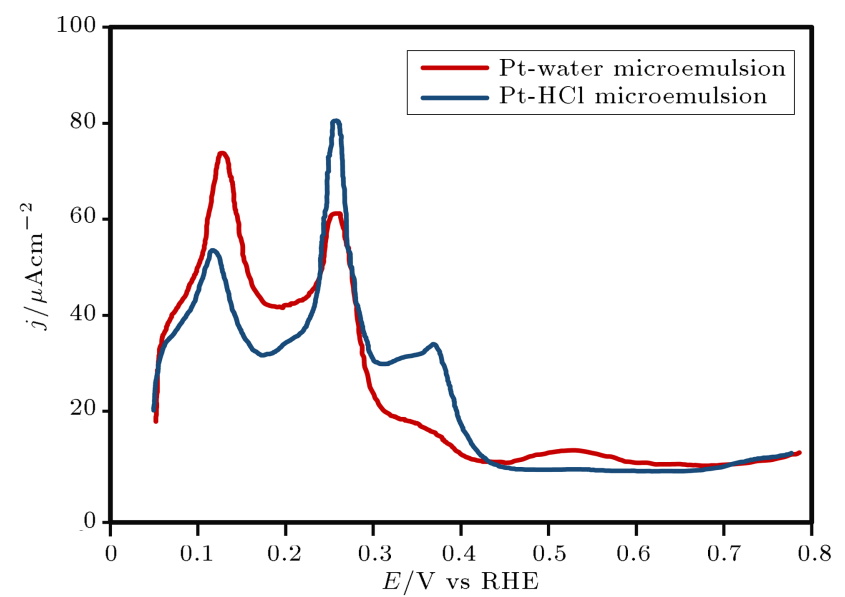

Figure 3. Voltameter diagram for platinum nanoparticles synthesized in water-microemulsion and $\mathrm{HCl}$-microemulsion systems. acceptor [20]. As is shown in the following mechanism, a six-electron reduction process is necessary to transform $p$-NP to $p$ - AP ( $p$-aminophenol):

$$
\begin{aligned}
& 2 P t+H_{2} \rightleftarrows 2 P t-H \\
& 6 P t-H+p-N P \rightarrow p-A P+6 P t+6 H^{+} .
\end{aligned}
$$

The reaction progress was monitored by measuring the absorption spectrum of $p$-NP as a function of time. After adding the $\mathrm{Pt} / \gamma-\mathrm{Al}_{2} \mathrm{O}_{3}$ nanocatalysts to the reaction mixture of $p$-NP and $\mathrm{H} 2$, a gradual decrease in the absorption peak at $400 \mathrm{~nm}$, related to $p$-NP, was observed. The preliminary experimental results confirmed that no hydrogenation reduction occurred in the absence of the catalysts. This result confirms that there is no non-catalytic reaction. The percentage of catalytic conversion of $p$-NP hydrogenation over $\mathrm{Pt} / \gamma-\mathrm{Al}_{2} \mathrm{O}_{3}$ nanocatalysts synthesized in $\mathrm{H}_{2} \mathrm{O}$-microemulsion and $\mathrm{HCl}(\mathrm{aq})$-microemulsion systems was calculated using Eq. (1), as reported in Table 1.

As a result, the efficiency percent of the catalytic reduction of $p$-NP over $\mathrm{Pt} / \gamma-\mathrm{Al}_{2} \mathrm{O}_{3}$ nanocatalyst synthesized in $\mathrm{HCl}(\mathrm{aq})$-microemulsion was found to be $100 \%$ after about $15 \mathrm{~min}$. On the other hand, in the case of $\mathrm{Pt} / \gamma-\mathrm{Al}_{2} \mathrm{O}_{3}$ nanocatalyst synthesized in $\mathrm{H}_{2} \mathrm{O}$ microemulsion system, the efficiency was observed as about $28.1 \%$ after 15 min (Table 1 ). This interesting result and excellent performance of the catalyst synthesized in $\mathrm{HCl}(\mathrm{aq})$-microemulsion can be explained based on the structure of the $\mathrm{Pt}$ nanoparticles dispersed on the alumina. As explained by the electrochemical results, the obtained voltammetric profile of $\mathrm{Pt} / \gamma-\mathrm{Al}_{2} \mathrm{O}_{3}$ nanocatalyst synthesized in $\mathrm{HCl}(\mathrm{aq})$ microemulsion represents the largest contributions at $0.35-0.37 \mathrm{~V}$ relating to the (100) ordered domains (Figure 3). It means that the catalytic reduction of $p$-NP over $\mathrm{Pt} / \gamma-\mathrm{Al}_{2} \mathrm{O}_{3}$ nanocatalyst is mainly accelerated by (100) site. On the other hand, this site can

Table 1. Percentage of catalytic conversion of $p$-NP hydrogenation over $\mathrm{Pt} / \gamma-\mathrm{Al}_{2} \mathrm{O}_{3}$ nanocatalysts synthesized in $\mathrm{H}_{2} \mathrm{O}$-microemulsion and $\mathrm{HCl}$-microemulsion systems.

\begin{tabular}{ccc}
\hline Time (min) & $\begin{array}{c}\mathbf{P t} / \boldsymbol{\gamma}-\mathbf{A l}_{\mathbf{2}} \mathbf{O}_{\mathbf{3}} \\
\text { Synthesized } \\
\text { in water }\end{array}$ & $\begin{array}{c}\mathbf{P t} / \boldsymbol{\gamma}-\mathbf{A l}_{\mathbf{2}} \mathbf{O}_{\mathbf{3}} \\
\text { Synthesized } \\
\text { in } \mathbf{H C l ~ 2 5 \%}\end{array}$ \\
\hline 5 & 4.8 & 26.2 \\
10 & 11.9 & 95.1 \\
15 & 28.1 & 100 \\
20 & 45.8 & 100 \\
25 & 51.8 & 100 \\
30 & 58.3 & 100 \\
\hline
\end{tabular}


facilitate electron transfer from donor $\mathrm{H}_{2}$ to acceptor $p$-NP through the above mechanism.

\section{Conclusion}

In this research study, $\mathrm{Pt} / \gamma-\mathrm{Al}_{2} \mathrm{O}_{3}$ nanocatalysts were prepared by using microemulsion method with different $\mathrm{pH}$ conditions for the first time. One w/o microemulsion contains $\left(\mathrm{H}_{2} \mathrm{O}+\mathrm{H}_{2} \mathrm{PtCl}_{6}\right) / n$-heptane/Triton $\mathrm{X}$ 100/2-butanol, and the other contains $(\mathrm{HCl}(\mathrm{aq})+$ $\mathrm{H}_{2} \mathrm{PtCl}_{6}$ )/n-heptane/Triton X-100/2-butanol. Characterization of the prepared nanocatalysts by X-ray diffraction and cyclic voltammetric methods showed that $\mathrm{HCl}$ content had significant effect on the shape and activity of the nanocatalysts. The structure effect on the catalytic activity of the prepared nanocatalysts was investigated by hydrogenation reaction of $p$-NP, as a reaction model. It is concluded that the activity of $\mathrm{Pt} / \gamma-\mathrm{Al}_{2} \mathrm{O}_{3}$ nanocatalyst synthesized in $\mathrm{HCl}(\mathrm{aq})$ microemulsion with (100) preferentially oriented $\mathrm{Pt}$ nanoparticles is strongly more than that prepared in $\mathrm{H}_{2} \mathrm{O}$-microemulsion system. These results open a new avenue to regulate activity and selectivity of the nanocatalysts prepared in microemulsion systems.

\section{Acknowledgment}

The financial support from Arak University and Iran National Science Foundation is gratefully acknowledged (Grant No. 95818034).

\section{References}

1. Bennett, C.O. and Che, M. "Some geometric aspects of structure sensitivity", J. Catal., 120, pp. 293-302 (1989).

2. Bond, G.C. "Supported metal catalysts: some unsolved problem", Chem. Soc. Rev., 20, pp. 441-475 (1991).

3. Sánchez-Sánchez, C.M., Solla-Gullón, J., VidalIglesias, F.J., Aldaz, A., Montiel, V., and Herrero, E. "Imaging structure sensitive catalysis on different shape-controlled platinum nanoparticles", J. Am. Chem. Soc., 132, pp. 5622-5624 (2010).

4. Oudar, J. "Hydrogenation reactions on platinum single crystals", Zeitschrift für Physikalische Chemie, 197, pp. 125-136 (1996).

5. Englisch, M., Jentys, A., and Lercher, J.A. "Structure sensitivity of the hydrogenation of crotonaldehyde over $\mathrm{Pt} / \mathrm{SiO}_{2}$ and $\mathrm{Pt} / \mathrm{TiO}_{2}$ ", J. Catal., 166, pp. 25-35 (1997).

6. Kooti, M. and Afshari, M. "Magnetic cobalt ferrite nanoparticles as an efficient catalyst for oxidation of alkenes", Scientia Iranica, F, 19, pp. 1991-1995 (2012).

7. Miyazaki, A., Balint, I., and Nakano, Y. "Morphology control of platinum nanoparticles and their catalytic properties", J. Nanopart Res., 5, pp. 69-80 (2003).
8. Long, N.V., Ohtaki, M., Hien, T.D., Jalem, R., and Nogami, M. "Synthesis and characterization of polyhedral and quasisphere non-polyhedral Pt nanoparticles: effects of their various surface morphologies and sizes on electrocatalytic activity for fuel cell applications", J. Nanopart Res., 13, pp. 5177-5191 (2011).

9. Long, N.V., Chien, N.D., Hayakawa, T., Matsubara, T., Ohtaki, M., and Nogami, M. "Sharp cubic and octahedral morphologies of poly(vinylpyrrolidone)stabilised platinum nanoparticles by polyol method in ethylene glycol: their nucleation, growth and formation mechanisms", J. Experimental Nanoscience, 7, pp. 133-149 (2012).

10. Arán-Ais, R.M., Solla-Gullón, J., Herrero, E., and Feliu, J.M. "On the quality and stability of preferentially oriented (100) Pt nanoparticles: An electrochemical insight", J. Electroanal. Chem., 808, pp. 433-438 (2018).

11. Cuenya, B.R. and Behafarid, F. "Nanocatalysis: sizeand shape-dependent chemisorption and catalytic reactivity", Surface Science Reports, 70, pp. 135-187 (2015).

12. Martínez-Rodríguez, R.A., Vidal-Iglesias, F.J., SollaGullón, J., Cabrera, C.R., and Feliu, J.M. "Synthesis and electrocatalytic properties of $\mathrm{H}_{2} \mathrm{SO}_{4}$-induced (100) $\mathrm{Pt}$ nanoparticles prepared in water-in-oil microemulsion", Chem. Phys. Chem., 15, pp. 1997-2001 (2014).

13. Martínez-Rodríguez, R.A., Vidal-Iglesias, F.J., SollaGullón, J., Cabrera, C.R., and Feliu, J.M. "Synthesis of $\mathrm{Pt}$ nanoparticles in water-in-oil microemulsion: Effect of $\mathrm{HCl}$ on their surface structure", J. Am. Chem. Soc., 136, pp. 1280-1283 (2014).

14. Martínez-Rodríguez, R.A., Vidal-Iglesias, F.J., SollaGullón, J., Cabrera, C.R., and Feliu, J.M. "Electrochemical characterisation of platinum nanoparticles prepared in a water-in-oil microemulsion in the presence of different modifiers and metal precursors", Chem. Electro. Chem., 3, pp. 1601-1608 (2016).

15. Soleimani, S., Salabat, A., and Tabor, R.F. "Effect of surfactant type on platinum nanoparticle size of composite $\mathrm{Pt} / \alpha-\mathrm{Al}_{2} \mathrm{O}_{3}$ catalysts synthesized by a microemulsion method", J. Colloid Interface Sci., 426, pp. 287-292 (2014).

16. Salabat, A. and Soleimani, S. "Ultrasonic irradiation and solvent effects on destabilization of colloidal suspensions of platinum nanoparticles", Particuology, 17, pp. $145-148$ (2014).

17. Soleimani, S. and Salabat, A. "Effect of various factors on the Pt nanoparticle size produced in a microemulsion system", Colloid Journal, 77, pp. 207-212 (2015).

18. Pradhan, N., Pal, A., and Pal, T. "Silver nanoparticle catalyzed reduction of aromatic nitro compounds", Colloid Surface A, 196, pp. 247-257 (2002). 
19. Vidal-Iglesias, F.J., Arán-Ais, R.M., Solla-Gullón, J. Herrero, E., and Feliu, J.M. "Electrochemical characterization of shape-controlled $\mathrm{Pt}$ nanoparticles in different supporting electrolytes", ACS Catalysis, 2, pp. 901-910 (2012).

20. Das, J., Aziz, M.A., and Yang, H. "A nanocatalystbased assay for proteins: DNA-free ultrasensitive electrochemical detection using catalytic reduction of p-nitrophenol by gold-nanoparticle labels", J. Am. Chem. Soc., 128, pp. 16022-16023 (2006).

\section{Biographies}

Alireza Keshavarz is a $\mathrm{PhD}$ student of Physical Chemistry at Arak University, Iran. He received his
MSc from Institute for Advanced Studies in Basic Sciences (IASBS) in 2013 in the field of physical chemistry. His research interests include surface chemistry and nanocatalyst.

Alireza Salabat is a Professor of Physical Chemistry at Arak University, Iran. He received BS (1991) in Applied Chemistry from Isfahan University of Technology and continued his field of study to obtain MSc (1994) and PhD (1998) from Tabriz University. He has worked as a Visiting Professor at Colloid Center of University of Bristol (2005-2006). His research interests include colloid science, surface chemistry, solution thermodynamics, polymer chemistry, nanocomposites, and nanocatalysts. 